\title{
Ethics, Communication, and Propaganda About Energetic and Environmental Topics
}

\author{
Francesca Marin ${ }^{1}$, Alberto Mirandola ${ }^{2}$ \\ ${ }^{1}$ Department of Philosophy, Sociology, Education and Applied Psychology (FISPPA), University of Padua, Padua, Italy \\ ${ }^{2}$ Department of Industrial Engineering, University of Padua, Padua, Italy
}

Email address:

francesca.marin@unipd.it (F. Marin), alberto.mirandola@unipd.it (A. Mirandola)

\section{To cite this article:}

Francesca Marin, Alberto Mirandola. Ethics, Communication, and Propaganda About Energetic and Environmental Topics. American Journal of Energy Engineering. Vol. 3, No. 6, 2015, pp. 78-85. doi: 10.11648/j.ajee.20150306.11

\begin{abstract}
This paper aims at disentangling and explaining the meaning of communication, which should not be confused with the mere transmission of information. The focus will be put on scientific and technological communication, mainly in the field of energetic and environmental topics. Communication is a profession practiced by speakers and writers working within the mass media (newspapers, television, internet, etc.), but other people are involved in communication issues, particularly when communication deals with scientific and technological topics. Scientists, technicians and professionals, and engineers in particular, have a great responsibility when participating in the spread of technical information, which should not be confused with propaganda, whose meaning is explained in the paper. The paper will be developed in two stages. Firstly, by offering a conceptual framework, it will be argued that communication, rightly understood, is a special kind of action that is characterized by an ethical commitment, which should permeate our daily life, in particular the professional experience. On the contrary, propaganda cannot constitute an authentic communicative context because it involves senders and receivers, and not interlocutors. Indeed, propaganda generally aims at influencing opinions, attitudes and actions of a specific target audience on the basis of senders' personal interest or ideological thinking. Secondly, practical examples will be provided in the scientific and technical fields, with particular attention given to energetic and environmental issues. In fact, this is a critical context, because people are generally not prepared to deeply understand this matter and can easily be manipulated. Some examples will show how a given reality can be partially presented or misrepresented when speaking about the concept of sustainability, the evaluation of health or safety risks, the assessment of the potentiality of renewable energy sources, the difference between energy sources and energy carriers, the interpretation of climate changes, or the ideological opposition to industrial initiatives.
\end{abstract}

Keywords: Communication, Information, Ethics, Propaganda, Technical Writing, Media, Public Perception, News

\section{Introduction}

"Environmentalism began with environmental communication": this sentence effectively explains that communication has a large influence on the public opinion and on one's relationships with others. Communication is also a profession, generally practiced by journalists, speakers of mass media, etc.

A professional speaker or writer should promote better relations with people (colleagues, customers, clients, citizens, society). He must know the audience he addresses and adapt his speaking or writing to the characteristics and the needs of this audience, using a suitable language. He should be conscious of his responsibility towards the others.
Professional writing or speaking must create relations with the audience, aiming to promote knowledge and achieve the common good. This attitude of professional writers or speakers is an example of "ethical communication". In the present paper, the conceptual setting of professional communication will be stated, emphasizing and examining in depth the meaning and the differences between ethical communication and propaganda.

Particular attention will be given to communication regarding scientific and technological topics, which are often dealt with not only by scientists and technicians, but also by politicians and journalists. It will be pointed out that these topics should be faced by people who have proper knowledge of them; their writing or speaking should be objective, oriented to the improvement of the society and/or the 
environment, and not influenced by ideology, personal profit or for the benefit of a given group of people (a political party, association, etc.).

\section{Propaganda and Communication}

Nowadays communication flows easily from a wide variety of sources, and information can be gathered by everyone, at every time and everywhere thanks to the availability of different and widespread communication devices and channels. Although there are positive effects of these communication processes, such as availability, accessibility and affordability of information, the risk of deception and intentional control of information is higher than it was in past years. For example, the use of strategies of persuasion, manipulation and propaganda is common, often hidden, and can be found in all aspects of daily life.

For the purpose of this paper, we will focus on communication processes that characterize professional experience, emphasizing and analyzing the meaning and the differences between ethical communication and propaganda.

Generally, propaganda is the spread of ideas and information aimed at influencing opinions, attitudes and actions of a specific target audience. ${ }^{1}$ This deliberate attempt to shape perceptions and direct behaviors arises from different motivations, such as private economic interests, political demagogy, and superficiality, and it is usually realized by presenting facts selectively (for example lying by omission) or in a distorted way. In this respect, a variety of approaches and devices are employed to circumvent or suppress the audience's ability to adequately judge the information. For example, an essential tool of propaganda is persuasion because its techniques and strategies aim to convince an audience and produce conviction. From this general definition, propaganda involves a communicative process, yet, can propaganda be totally included in the communicative field? To specify, can we really say that a professional who is making propaganda is communicating in the true sense of the word?

At first blush, we could provide an affirmative answer to such questions because propaganda is a dissemination of information, not objective and well-documented of course, but selective and distorted. Nowadays, when we think about communication we still attempt to describe it by the so-called "transmission model" or "standard view of communication". This model describes communication as a means of sending and receiving information, that is, as the mere transmission of a message. To exemplify, by communicating, information is sent as a message from a sender to a receiver, who is the target of the message. As a consequence, according to this model, communication is a linear and transactional process;

\footnotetext{
1 It is difficult to define propaganda because on the one hand it can and does find its place in many fields such as advertising, entertainment, politics, professional experience, and on the other hand it assumes different forms, such as agitative and integrative propaganda, and white, grey and black propaganda. For all these distinctions, see Jowett, O'Donnell (20156), pp. 1-33; Brunello (2014), pp. 171175.
}

it is always unilateral, unidirectional and it is good or successful when the transmission of a message occurs effectively, removing anything that may slow down this transmission. In this respect, communication is regulated by the principles of efficacy and efficiency: to communicate effectively, information should be sent in a short time and with a minimal waste of resources. From a moral point of view, this model reduces the value of a communicative process to the proper functioning of a system, which is supposed to be effective and efficient.

Nevertheless, can communication be described as the mere transmission of a message from a sender to a receiver? Actually, the verb "to inform", and not "to communicate", suggests the act of sending and receiving information. To specify, communication may include the transmission of information, but cannot be reduced to it and this is due to the particular human interaction that characterizes every communication process - indeed, all the subjects involved in this process (speakers) are considered, from the beginning, as interlocutors. As a consequence, even when communication includes the transmission of information, those who receive the message are not deemed as mere receivers, but as interlocutors, that is, as speakers who cooperate within the communicative context. Rightly understood, communication is the creation of a shared space; in other words, to communicate means to disclose a shared space among interlocutors. ${ }^{2}$

These considerations are confirmed by the etymology of the word "communication" - indeed, this term derives from the Latin noun communicatio, which refers to the Latin verb communicare meaning "to make common", "to give to someone a share of something". 3 The notion of sharing or imparting is then intrinsic to the term "communication" because to communicate means to create a shared space of joint participation. As a consequence, involving interlocutors (and not merely senders and receivers), a communicative process is bidirectional.

On the contrary, propaganda is always unilateral and unidirectional and cannot constitute an authentic communicative context. Indeed, propaganda is the mere transmission of a message which has been intentionally selected and distorted by senders in order to influence receivers' opinions, attitudes and actions. In this way the receiver of the message is never considered as an interlocutor.

\section{Considering Communication in the Category of Action}

The previous analysis of the meaning and differences between propaganda and communication addresses a further relevant aspect of the latter: by involving interlocutors, the communicative field is characterized by an ethical commitment because it is oriented toward reaching understanding. As suggested by the German philosopher

\footnotetext{
2 See Fabris (2006).

3 See Peters (1999), p. 7.
} 
Jürgen Habermas within his communicative action theory, communication cannot be reduced to merely describing the world because it is a special kind of action ${ }^{4}$ which is of intentional character and fulfills a certain function, which is to reach a shared understanding. ${ }^{5}$ The possible achievement of mutual understanding is thus included within the communicative practice. In this way, the communicative field is characterized by a normative background, that is, by moral principles which are implicitly presupposed by all interlocutors. To specify, for Habermas the communication between a speaker and a listener inherently involves the following universal validity claims: comprehensibility, truth, sincerity (or truthfulness) and rightness. In fact, it is only on the basis of the reference to these validity claims that we might accept or contest (reject as invalid) someone else's statement, considering it comprehensible or incomprehensible, true or false, fair or unfair and having or lacking a truthful attitude by the speaker. Quoting Habermas, «The concept of communicative action presupposes language as the medium for a kind of reaching understanding, in the course of which the participants, through relating to a world, reciprocally raise validity claims that can be accepted or contested». ${ }^{6}$ These claims thus have intersubjective validity, are often raised only implicitly by the speakers, and are open to both criticism and justification.

According to this framework, ethics is intrinsically involved in the communicative field. In particular, as communication is oriented toward reaching understanding, all interlocutors are tacitly involved in the practice of giving reasons: when required, speakers may be called to explain and rationally justify their speech act as true, correct and authentic. In other words, rightly understood, communication is a field of moral choices and decisions: communicative processes are characterized by an ethical commitment and all participants are responsible for the fulfillment of a shared understanding.

On the basis of the previous considerations we could say that, in order to develop a good communicative practice, criteria of objectivity, rightness, honesty, truth, and sincerity should firstly be fulfilled. Secondly, all subjects involved in this practice should be recognized as interlocutors and be treated in terms of equality and parity. Thirdly, the speaker should know the content of what he is communicating, which requires an authentic commitment of data checking and updating. Finally, faced with a propagandistic dissemination of ideas and information, a good interlocutor does not passively adopt its content, but rather reads up on and carefully examines this information. Otherwise he would be reducing himself to a receiver.

\footnotetext{
4 As argued by philosopher J.L. Austin within his speech act theory, many utterances are performative because these statements express the action character, meaning they perform an act by the fact of their being uttered. An example of performative utterance is promising because by uttering "I promise" I am not merely saying something, I am performing an act of promise directed towards other people. See Austin (1962)

5 Habermas (1984). For an analysis of Habermas' discourse-based morality, see Donald Moon (1995) and Rehg (2011).

6 Habermas (1984), p. 99.
}

\section{Professional Experience and Communication}

From our point of view, a professional should be aware of all aspects mentioned above for the following reasons: a profession is a particular working activity socially recognized and carried out by those who have specific competences and knowledge acquired through lengthy academic and practical training. A profession is then characterized by a public commitment: when a professional is asked for a certain professional service, he does not relate to only one client, but to the entire community. This aspect is confirmed by the etymology of the word "profession": indeed, this term derives from the Latin verb profiteri, which means "to declare aloud or publicly". In other words, those who practice a profession are involved in a particular human relationship and are making a professional commitment towards others that do not possess their knowledge and skills. As a consequence, the professional-client relationship is always asymmetrical, that is, characterized by an inequality of expertise among the subjects involved, and it is, by its very nature, a fiduciary relationship. Indeed, the professional holds the balance of power and the client is therefore forced to trust him.

The aspects of public commitment and of the fiduciary character of every professional-client relationship should thus be taken into account within the communicative processes that characterize professional experience. When professionals communicate, they are addressing the entire society and should be aware that those who do not possess their knowledge and skills will be forced in some ways to trust them. Professionals thus ought to be honest and accurate in all communication and adapt their speaking or writing to the characteristics and needs of the audience.

All of these aspects are addressed by professional codes, which are a form of self-regulation aimed at dealing with the problem of asymmetry in the relationship between professional and client and at avoiding any possible instrumentalization of the latter. For example, the Code of Ethics of Engineers promulgated by the American Society of Mechanical Engineers (ASME) states that in the fulfillment of their professional duties "Engineers shall issue public statements only in an objective and truthful manner". ${ }^{7}$ As a consequence, by disseminating propaganda, a professional intentionally selects and distorts a message in order to influence clients' opinions, attitudes and actions. In this way, an instrumentalization of clients, but even of the entire society, is at stake.

\section{Technical and Scientific Communication}

Communication regarding scientific or technical subjects is tricky, because the people it addresses are generally not

7 ASME (1998). 
prepared to fully understand this matter and may be swayed by misleading ideas if the speaker has a personal interest in influencing them. The ethical codes of some technical associations are based on concepts that are considered milestones. For example, the ASME Code of Ethics previously mentioned states that "Engineers shall hold paramount the safety, health and welfare of the public in the performance of their professional duties". ${ }^{8}$ However the professional duty of engineers is not only to design machines, instruments or processes, but also to inform the people correctly about what is really dangerous for health or safety and how to assess the cost/benefit ratio of a given technology. This means that engineers are not only builders and designers, but also have social responsibilities in communicating with policy makers and people about scientific and technical subjects.

In the mass media, the industrial society and its products (machinery, devices, chemical processes, plants) are often associated with many kinds of dangers, a lack of safety, environmental pollution, etc. According to this feeling, public opinion, generally oriented by certain "opinion makers", thinks that these negative features often prevail over the positive effects and are harmful for people's health and safety. To a certain extent this is true; but is only a part of the truth. In fact, technology has brought about the progress of medicine, the creation of products and systems for personal hygiene, the development of safety standards and corresponding equipment to reduce the effects of dangerous events; and, above all, the availability of a great number of resources which have made it possible to sustain a growing population and increase man's life span in the developed countries. Correct information must consider all these features: the natural and human systems are very complex and their equilibria are difficult to analyze, understand and explain.

Science and technology run together through the years and influence each other, causing an increase of knowledge and awareness about the development and interaction of human actions and natural events. Scientists and technicians have inside themselves the "culture of doubt", which promotes knowledge through research of new ways, processes and products. This culture is in contrast with the "fideistic" and ideological attitude of certain groups of persons who tend to simplify knowledge, are inclined to be self-confident in their own truth and refuse to modify their ideas. The information spread by these people, or people inspired by personal or political interest, is not reliable and can be misleading and sometimes dangerous.

Nowadays a lot of news and information about technical and scientific topics can be obtained from the web. However, everyone can introduce information into the web without any filter or controls. Therefore, on the web we can find both information and misinformation, communication and propaganda, truth and falsities. Certainly, this source of information can be very useful and contribute to knowledge when used in the right way by wise and qualified people, but on the Internet we can find everything and its opposite, in

8 Ibidem. which case knowledge is reduced to mere opinion.

The scientific environment has also its communication problems. Scientific information is commonly spread via papers written by scientists and researchers. This is a good practice; however, some researchers write a large number of papers in order to improve their academic carrier ${ }^{9}$ and the haste and anxiety of publishing often does not result in good quality. Even though these papers are generally submitted for peer review, these reviews are not always reliable. In fact, each outstanding reviewer is requested to examine many papers and sometimes they do not have enough time to elaborate upon their content: their review may sometimes be superficial. This is why the Impact Factor, which is generally considered a good indicator, is not always trustworthy. In any case, peer review is overall a good assessment system.

A practice used by scientific journalists when dealing with controversial topics is "balance treatment": the journalist presents the opposite opinions of scientists or technicians belonging to different currents of thought. The idea is to compare and then assess their different opinions, but if these opinions are well expressed and documented by apparently reliable arguments, where does the truth lie? Balance treatment can create more confusion than knowledge.

In conclusion, sometimes it is very difficult to distinguish between truth and falsity. Professional writers and speakers have a great responsibility towards the society when presenting scientific and technical topics.

\section{Communication About Energetic and Environmental Topics}

According to the ASME code, "Engineers should consider environmental impact and sustainable development in the performance of their professional duties". ${ }^{10}$ They should not only act accordingly in developing their work, but also inform people about the interaction between energy, economy and the environment; the meaning of sustainable development, which is connected to science, technology and economy, should be correctly explained. Sustainability does not simply refer to the impact of certain technologies on the environment, but is a more complex concept, because it also deals with:

- the resources needed to sustain human population (more than 7 billion in 2015 and still increasing);

- the social and economic impact;

- the constraints of nature and technology;

- the responsibility towards future generations.

These features are particularly challenging: technical and scientific communication should inform the public without falling into demagogy. For example, when it comes to resources and social organization, some opinion leaders of the so-called "green" people think that generally it would be

9 In this respect, think about the academic "publish or perish" mandate (i.e. produce published work or you won't get tenure) which is clearly pervasive and can contribute to lots of bad writing.

10 Ibidem. 
desirable to let nature simply run with its own rhythms. But they forget that, since the beginning of history, human beings have always interacted with nature and modified it, by abating forests and replacing them with farming, diverting rivers, breeding and eating animals, etc. They do not consider that nowadays our planet is very crowded; sometimes it is necessary to use the possibilities offered by technology, which is a valuable means that can prevent natural disasters or other dangerous events from occurring. Of course, technology must be used with moderation and wisdom. Energy conservation is a goal in all fields of activity: seeking high efficiency and rational organization of energy systems is paramount. Nevertheless, it is important to distinguish utopian projects and their effects from realistic ones.

As for renewable energy sources, their real potential must be explained to people, to avoid unrealistic reliance upon them. These sources have a very important positive characteristic: they are renewable for indefinite time and have a low environmental impact during operation. However, they also have some negative features:

a) Very low power density: the collection of significant amounts of power requires large surfaces (i.e. a huge request of areas for power plants) and hence a high consumption of materials, which must be extracted from the earth and treated by industrial manufacturers to obtain the requested products. Therefore, while the environmental impact during operation is negligible, the impact for the construction of the plants, their maintenance and final decommissioning and disposal is higher.

b) Unpredictable and variable availability, not consistent with the needs of the users. These features require the use of integrative and/or storage systems, often based on the exploitation of non-renewable resources.

As a consequence, it is utopian to think that renewable sources will be able to cover a large percentage of energy needs within a few decades. Consider the fact that in 2015 fossil fuels cover about $85 \%$ of the total energy supply in the world. Will it be possible to transform the world economy so rapidly in such a way? The authors think that spreading these ideas is misleading; but very often these concepts are developed by newspapers and other communication systems (Internet, television, etc.).

These issues are very complex: to face them, it is important to be able to "reason by systems", which is typical of modern scientists. In any case, the so-called "3 E's" (Energy, Environment, Economy) must always be considered, because these three aspects are closely connected to each other. There is a conflict between the need for resources in our crowed world, the environmental impact and the economy: finding the most acceptable compromise between these features is a very challenging problem for politicians, scientists, economists and engineers. These concepts must be correctly explained to the people.

The products delivered to the environment through the combustion of fossil fuels (gases, ashes, etc.) are polluting, of course: all the methods and systems able to abate and limit this pollution are paramount. Much progress has been made in this field: the pollution of engines, boilers, furnaces, etc. has been reduced year by year. People must be informed about this issue. Some incorrect information can be found regarding the pollution of our cities. While it is true that the concentration of products in the atmosphere often exceeds the limits imposed by regulations in some areas, these limits, stated in recent years, are very low. The concentration of products in some crowded areas, even though it may often go above the limits, is much lower than in the past decades (when regulations did not exist), thanks to the progress of technology. Can we remember the environmental situation in London or in some cities of the Po Valley in the 1950's or 1960's? This situation is much better now. Nevertheless, newspapers and television almost every day inform us about the overrunning of limits and its terrible effects, without saying anything about the improvements mentioned above. Incorrect information is not only telling lies, but also hiding part of the truth.

A recurring piece of information in the mass media is the number of deaths caused by pollution in a certain area. Is it really possible to make this assessment so precisely? And if this information is true, how can we explain that the length of human life in the cities of the developed countries has been continuously increasing?

A different question is the situation in some developing areas, where rampant industrialization brings huge problems. These countries should learn some lessons from the history of the "old" industrialized economies; it does not make sense that the new industrial countries should try to follow the path of the old ones. The recent methods now offered via scientific and technological knowledge can help foster more sustainable development, without making the same mistakes of the past.

A topic which gives rise to continuous controversy is the disposal or treatment of rubbish. The amount of rubbish produced in developed countries is very high; too high certainly. An obvious way to face this problem is through a significant reduction of this production. But the effects of this policy can be reached in the long term through suitable organization. In the meantime, the rubbish must be treated in some way. The classical solution in the past was to dispose of it into dumping grounds. Of course, this is not a good solution. A rational policy is the combination of:

- waste separation;

- recycling of some of the rubbish;

- incineration of a suitable part of the rubbish with energy conversion;

- disposal of the remaining part and incineration residues into well-managed dumping grounds.

Generally, incineration provokes heated discussions and is obstructed in every way, claiming that this technology is highly polluting and is harmful for public health. First of all, it is obvious that the combustion of every substance causes the release of products into the environment. This is why many technological systems have been introduced to minimize these emissions and are applied in all the plants 
burning fuels, fossil or not. A typical statement opponents make is that incineration causes the emission of unacceptable amount of macro- and micro-pollutants, mainly dioxin. If we consider the modern incinerators, this is not true: the emission of dioxin is close to zero; this result is obtained by the use of abatement systems and a continuous control of the combustion temperature, which must be kept between $850^{\circ}$ and $950^{\circ} \mathrm{C}$. Combustion is rigorously controlled on-line not only by plant operators, but also by public assessment boards. On the contrary, relatively high amounts of dioxin and other harmful products are emitted, for example, during violent demonstrations, when rubbish skips and other devices are burnt at low temperature in the streets among the people. The mass media generally gives glaring information about the (previously mentioned) opposition to incineration, but does not emphasize the emissions generated during those demonstrations.

The opposition to the incinerators is only one example of what can be observed whenever a project for a new industrial plant is submitted to a local administration: the initial reaction of the people is to strongly oppose it, a typical NIMBY reaction. Generally this attitude of the people is not rationally motivated, but is due to the influence of the mass media and small groups of individuals who are "specialized in opposition": they spread incorrect information about the consequences of the plants' operation on public health or safety. And they find a lot of followers: in fact, people are more attracted by negative than positive news, and when a danger is supposed to occur, they are prone to believe it. This is why it is very important to spread reliable information; scientists and technicians' responsibility in this matter is crucial. Facing a problem like this, the correct thinking is: if the plant is not built, what would the alternative realistic solution be? And would it be better or worse? And what about the cost and the social consequences of each alternative?

As a matter of fact, every human action includes a certain degree of risk and it is important to give this information to the people. Without risk, nothing would be done, no contribution to knowledge would be offered and each action would be bureaucratic and devoid of intelligence. The problem is the acceptability of an action or event having a given kind of risk, which mainly depends on three factors: ${ }^{11}$ the probability of the occurrence of a danger, its consequences if the danger itself occurs, and the benefits coming from that action. These items must be carefully assessed and compared. Of course, this assessment should be performed by experts, weighting all the aspects and considering the general good of the community and the environment. Hence, the experts have the additional responsibility of informing the authorities and the people directly, or through mass media.

Generally, the people and also many politicians do not know what the difference is between "energy sources" and "energy carriers". One of the authors remembers that a

11 European Commission (2000) certain politician, during an interview, said that "hydrogen will be the energy source of the future". This statement is not correct and creates confusion and false expectations among the audience: hydrogen is not a source, but, like electricity, is a transformation product, i.e. a carrier.

A question that must be carefully presented and discussed is that of the public incentives granted to encourage the startup of a new technology, for example an innovative system exploiting renewable energy sources. In the authors' opinion, the incentives, paid by the community, can be granted for a limited time and should not be too high: in the long term, every technology should be self-sustaining, otherwise it would charge the community unacceptably. Correct information has to be spread regarding this matter.

\section{Climate Changes and Information}

The climate on the earth is the result of delicate and complex equilibria, which have been ruled by natural phenomena throughout the centuries since the origin of our planet. ${ }^{12}$ Many different parameters influence the climate, mainly depending on the solar system: they determine the global and local temperatures, the composition of the atmosphere, the greenhouse effect, etc.

In the history of the world these parameters have seen remarkable variations; it may be said that the climate is continuously varying. Generally these variations have been very slow, but sometimes accelerations have been caused by specific causes. Human beings' curiosity about climate has pushed them to observe and study it since the prehistoric age, when the changes of the weather were mainly ascribed to the whims of gods.

In modern society, science and technology interact to give rational explanations to these phenomena. Many efforts are being made to assess the influence of the various parameters that are likely to determine the climate and the local weather; the possibility of forecasting short-term weather and the long-term trends of the climate is one of the main targets of these studies.

Understanding the mechanisms which regulate the climate is very challenging, because the interaction of multiple parameters can hardly be expressed by suitable systems of equations. Moreover, the values and the trends of these parameters from the past are not well known, because only in recent years have the measurement techniques, combined with proxy data, given reliable results.

This difficulty should encourage caution: scientists, aware of these difficulties, are continuously trying to improve their knowledge in this field and approach acceptable results step by step, i.e. slowly. However, a problem arises when politicians intervene and interfere with them. Generally politicians are not guided by the wish of obtaining knowledge, but by political interest and/or ideology. Therefore, the results of research are bent to a typical target of politicians: politics needs short-term solutions to get consensus, even though these solutions are not

12 See Behringer (2007) 
easy to reach. This attitude leads them to misrepresent the truth or hide part of it.

Returning to the question of climate, at present the prevailing current of thought is that nowadays the earth's climate is affected almost completely and exclusively by human activities, and particularly by the amount of greenhouse gases (mainly $\mathrm{CO}_{2}$ ) emitted into the atmosphere. ${ }^{13}$ The supporters of this statement are generally self-confident and self-referential, even if some other scientists ${ }^{14}$ think that the influence of nature, which was the motor for the climate's changes throughout the whole history of our planet, cannot have become irrelevant in only a few decades. Atmospheric pollution must not be confused with climate; everyone accepts that preserving the environment and conserving natural resources are necessary, but this does not mean that political actions will be able to influence the climate significantly.

Once again, science should be cautious when dealing with such difficult problems, and communication should take this into account. On the contrary, the scientists who are not in line with the majority are often derided and deprived of research funds by "politically correct" lobbies or associations. At the current status of research, knowledge of past climate trends and causes is still uncertain because of the lack of reliable measurements, proxy data and testimonies. This uncertainty does not help us to completely understand the influence of countless parameters and events. In conclusion, these difficulties should result in more humility and caution in discussions of these issues, leaving room for doubt, which is the correct attitude held by the serious scientists and should also be that of the mass media.

\section{Conclusion}

Focusing on communication and propaganda about energetic and environmental topics, the aim of this paper was to address the ethical commitment that inherently characterizes communicative practice: involving interlocutors, and not merely senders and receivers, communication is the creation of a shared space and is oriented toward reaching understanding. As a consequence, communicative practice cannot be reduced to the transmission of information (although it might include this aspect) and propaganda is not an authentic communicative context because it involves senders and receivers (as noted, the former intentionally selects and distorts a message in order to influence the latter's opinions, attitudes and actions).

Communication is thus a field of moral choices and decisions, and all participants are responsible for the fulfillment of a shared understanding. Applied to scientific and technological communication, this means that scientists, technicians and professionals, engineers in particular, bear a great responsibility with respect to the spreading of technical information. Indeed, their communication should fulfill the

13 See Intergovernmental Panel on Climate Change (IPCC). 14 In this respect, see Scafetta (2000) and Fred Singer (2008). criteria of objectivity, rightness, honesty, truth and sincerity in order to conveniently direct both citizens' actions and politicians' decisions. Furthermore people this communication addresses cannot passively accept its content: to be interlocutors, and not mere receivers, they should read up on and carefully examine this information.

In conclusion, the development of a good communicative practice requires that all participants acknowledge the ethical commitment intrinsic to communication. Nevertheless, this acknowledgement is a necessary, but not sufficient, condition: for example, someone might be aware of the ethical dimensions of communication yet decide to spread propaganda. Indeed, the promotion of a good communicative practice should move from the so-called "question of meaning", that is, why we should encourage good communication. In other words, why should we be interlocutors, and not mere senders and receivers? There are basically two closely related reasons. Firstly, a good communication safeguards the self and the other because it avoids the achievement of the former to the detriment of the latter and vice versa. Secondly, promoting good communication means setting up the conditions for the communication to continue itself: indeed, in the absence of interlocutors, other speech forms such as propaganda can always be more vociferously encouraged up to a point where the space for interlocution is completely closed.

\section{References}

[1] American Society of Mechanical Engineers (ASME), Code of Ethics of Engineers, June 10, 1998 (http://web.mit.edu/2.009/www/resources/mediaAndArticles/ ASME_ethics.pdf).

[2] Austin, J.L. (1962), How to Do Things with Words, Oxford University Press, Oxford.

[3] Behringer, W. (2007), Kulturgeschichte des Klimas. Von der Eiszeit zur globalen Erwärmung 5, aktualisierte Auflage, C.H. Beck, München (English Translation: A Cultural History of Climate, Polity Press, London 2009; Italian translation: Storia culturale del clima, Bollati-Boringhieri, Torino 2013).

[4] Brunello, A.R. (2014), A Moral Compass and Modern Propaganda? Charting Ethical and Political Discourse. Review of History and Political Science, Vol. 2, Issue 2, pp. 169-197.

[5] Donald Moon, J. (1995), Practical Discourse and Communicative Ethics, in S.K. White (ed. by), The Cambridge Companion to Habermas, Cambridge University Press, Cambridge, pp. 143-164.

[6] European Commission, First Report on the Harmonisation of Risk Assessment Procedures, 26-27 October 2000 (http://ec.europa.eu).

[7] Fabris, A. (2006), Etica della comunicazione, Carocci, Roma.

[8] Fred Singer, S. (2008), Nature, Not Human Activity, Rules the Climate; Report of the NIPCC, The Heartland Institute, Chicago.

(https://www.heartland.org/sites/all/modules/custom/heartland _migration/files/pdfs/22835.pdf). 
[9] Habermas, J. (1984), The Theory of Communicative Action 1. Reason and the Rationalization of Society, Polity Press, Cambridge.

[10] Intergovernmental Panel on Climate Change (IPCC): Assessment Reports AR1 (1990), AR2 (1995), AR3 (2001), AR4 (2007), AR5 (2013).

[11] Jowett, G.S., and O'Donnell, V. $\left(2015^{6}\right)$, Propaganda \& Persuasion, SAGE Publications, Singapore.

[12] Peters, J.D. (1999), Speaking into the Air: A History of the
Idea of Communication, The University of Chicago Press, Chicago.

[13] Rehg, W. (2011), Discourse Ethics, in B. Fultner (ed. by), Jürgen Habermas: Key Concepts, Acument, Durham, pp. 115139.

[14] Scafetta N., Climate Change and Its Causes. A Discussion about some Key Issues, Science \& Public Policy Institute, March 182000.

http://scienceandpublicpolicy.org/images/stories/papers/origin als/climate_change_cause.pdf. 